\title{
EVALUATION AND APPLICATION OF THE ORYZA (v3) RICE MODEL UNDER DIFFERENT NITROGEN LEVELS IN LIAONING PROVINCE, CHINA
}

\author{
WU, Y. X. ${ }^{1}-$ WANG, S. ${ }^{1}-$ YIN, H. ${ }^{1 *}-$ JIA, B. Y. ${ }^{1}-$ HuANG, Y. C. ${ }^{1}-$ Chen, P. S. ${ }^{2}-$ GuO, Y. Y. ${ }^{1}$ \\ ${ }^{1}$ College of Agronomy, Shenyang Agricultural University, Shenyang 110866, China \\ ${ }^{2}$ Ecometeorology and Satellite Remote Sensing Center of Liaoning, Shenyang 110001, China \\ *Corresponding author \\ e-mail: snyinhong@syau.edu.cn
}

(Received $18^{\text {th }}$ Aug 2021; accepted $23^{\text {rd }}$ Nov 2021)

\begin{abstract}
Climate change and the growing-demand for food security force growers to identify ways to improve both food production and resource-utilization effectiveness. Liaoning province is one of the major rice (Oryza sativa L.) production regions of China (CL), accounting for about $10 \%$ of the total national japonica cultivation area. In this study, the experimental regions were divided into five rice agroecological zones based on the difference in the planting area and climate conditions. Four nitrogen $(\mathrm{N})$ management levels were designed by the application amount of $\mathrm{N}$ fertilizer. ORYZA (v3) model was calibrated, validated and applied to simulate yields under four $\mathrm{N}$ fertilizer levels. The results showed that ORYZA (v3) can describe grain yield and above-ground biomass well, and it can be applied to simulate growth in CL region. Scenario-analysis indicated that the simulated grain-yield responded strongly to a low nitrogen level. However, there was no significant grain-yield increase under more N. Significant spatial variation in the grain-yield was observed at different levels. Compared to regions with limited temperature and light resources during the rice growing-periods, the regions with more optimal conditions showed higher grain-yields under all four $\mathrm{N}$ levels.
\end{abstract}

Keywords: climate change, yield, fertilizer, agriculture, crop

\section{Introduction}

Rice (Oryza sativa L.) is one of the most important staple food crops which feeds more than half of the world's population (Fan et al., 2016). China is an important rice production country, wherein the rice planting area accounted for $26.1 \%$ of the total grain-crop area, and the rice production accounts for $32.1 \%$ of the national total grain crop production (National Bureau of Statistics of China, 2016). Hence, rice production is vital for the food security in China. To meet the growing populational demand for food, people continuously improve the way of cultivation and management to increase rice yields.

Nitrogen $(\mathrm{N})$ is the most important plant nutrient in crop yield determination and the fertilizer is the major $\mathrm{N}$ source for modern agricultural systems (Mae, 1997). To increase rice yields, farmers often apply excessive amount of $\mathrm{N}$ fertilizers. In China, the average $\mathrm{N}$ application-rate in rice production is approximately $180 \mathrm{~kg} \mathrm{ha}^{-1}$, which is higher than that in most countries and as much as $75 \%$ above the global average. Rice crops in China consume about $37 \%$ of the total $\mathrm{N}$ fertilizer used for rice production in the world (Buresh and Witt, 2002; Roelcke et al., 2004; Peng et al., 2010). However, excessive usage of $\mathrm{N}$ has greatly decreased the economic return and also placed a heavy economic burden on farmers (Zhang, 2007). It can cause many issues such as low Nefficiency in the soil, leaching, volatilization, nitrification of $\mathrm{N}$, even destroying ecological balances and causing environmental hazards (Cheng et al., 2021). Moreover, 
over-application of $\mathrm{N}$ often induces rice lodging and pest damage resulting in yield and quality reduction. Further increase in $\mathrm{N}$ application to croplands is unlikely an effective method for increasing crop yield (Tilman et al., 2011).

Process-based crop models are important tools in modern agricultural research. The modeling method is time-saving and cost-effective and suitable for the extrapolation from site-specific experiments to larger spatial and temporal scales (Ling et al., 2019). ORYZA2000 is a robust model which provides reliable predictions for rice growth and yield in irrigated systems ( $\mathrm{Li}$ et al., 2017) and has been widely used in modeling rice growth all over the world (Rani et al., 2011; Soundharajan and Sudheer, 2013; Kim et al., 2015). ORYZA (v3) is an advanced version of ORYZA2000. ORYZA series models can be influenced by environmental conditions, crop management, and cultivar characteristics (Li et al., 2013, 2016, 2017).

The Liaoning province is an important japonica rice production region in China. The rice planting area in Liaoning accounts for approximately $10 \%$ of the national japonica rice area (National Bureau of Statistics of China, 2016). Rice yield in this region can significantly influence the local food supplies. For the rice production in Liaoning, high-N fertilizer is applied at average levels of 200-300 kg ha-1 and even $350 \mathrm{~kg} \mathrm{ha}^{-1}$ in some area (Yu et al., 2009). Until now, there has been no case-study on the application of ORYZA (v3) model under different $\mathrm{N}$ levels in the Liaoning province. The objectives of this study were to (a) calibrate and evaluate the performance of ORYZA (v3) for simulating rice development and yields under nitrogen-limited conditions in different agro-ecological zones in Liaoning and (b) apply ORYZA (v3) to investigate yield response to $\mathrm{N}$-application rates.

\section{Materials and methods}

\section{Study area}

The study area includes the main rice-growing areas of Liaoning province (CL), which was divided into five distinct agro-ecological zones based on the difference in the planting area and climate conditions (Figure 1). Huanren (CL1), Donggang (CL2), Liaozhong (CL3), Kaiyuan (CL4), Dawa (CL5) were respectively selected as the rice planting-sites in each agro-ecological zone. Two-three study sites were chosen within each agro-ecological zone, and a total of 18 sites (five experimental sites and 13 representative sites) were selected in the end. The spatial distribution of these sites was shown in Figure1.

\section{Data sources}

The experimental data sets used to calibrate and validate the crop model were derived from field experiments conducted from 2017-2019 (presented in Table 1). In this study, five widely planted local high-yielding rice cultivars were used in these experiments and assumed to be area-specific (Table 1).

On this basis, a database was generated from a rice field study in different areas with four nitrogen fertility management practices. The database was used to evaluate the ORYZA (v3) model. On every test site, experiments were performed by a completely randomized block design (CRBD) with three replications. The area of each experimental plot was $6 \mathrm{~m} \times 1.8 \mathrm{~m}$ (length $\times$ width). To analyze surveyed yield-levels in different regions, the Stanford formula (Eq.1-Eq.2) was used to calculate the amount of 
$\mathrm{N}$ applied in five testing-points. Four nitrogen fertilizer levels, namely the basic yield level (Yck), farmers' yield level (Yfp), high-yield and efficient yield level (Yhh), and super-high-yield level (Ysh) were used in this study. A diverse distribution for a specific fertilization-treatment was identified among the five areas (Table 2). Base fertilizer was applied 1d before sowing, and the tiller and jointing fertilizer were applied at the corresponding periods. All other management practices were the same for all plots following local standards, including the control of plant diseases, insect pests and weeds etc.

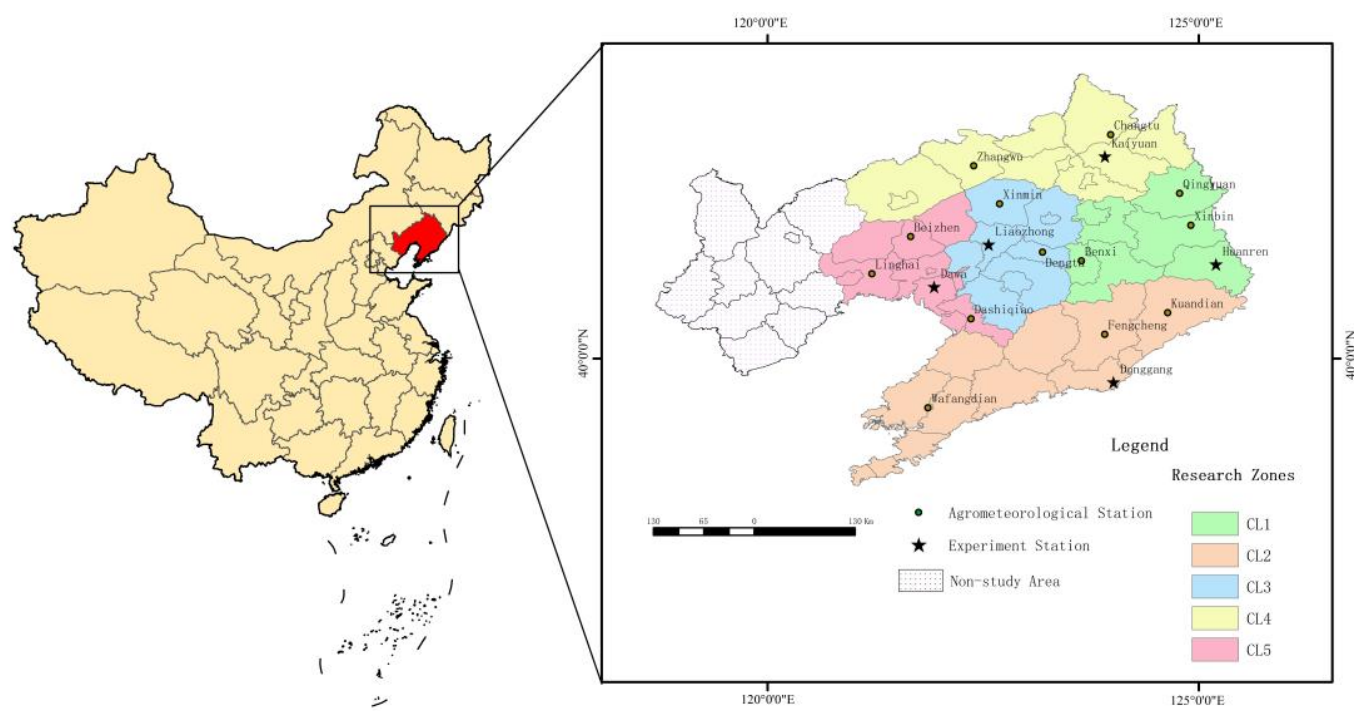

Figure 1. Distribution of rice representative sites and agro-meteorological observation stations in each region of the study area. Among them, CL1 represents the rice cultivation area in the eastern hilly area, CL2 represents the rice cultivation area in the coastal plain, CL3 represents the rice cultivation area in the central plain, CL4 represents the rice cultivation area in northern plain and CL5 represents Liaohe Delta rice planting area

Table 1. The database was divided into two samples, calibration data set (I) and validation data set (II)

\begin{tabular}{c|c|c|c|c}
\hline Area & $\begin{array}{c}\text { Experimental } \\
\text { station }\end{array}$ & Cultivar & $\begin{array}{c}\text { Calibration data set } \\
\text { ( I ) }\end{array}$ & $\begin{array}{c}\text { Validation data set } \\
\text { (II) }\end{array}$ \\
\hline CL1 & Huanren & Shendao529 & $2017-2018$ & 2019 \\
CL2 & Donggang & Shendao505 & $2017-2018$ & 2019 \\
CL3 & Liaozhong & Beijing 1 & $2017-2018$ & 2019 \\
CL4 & Kaiyuan & Tiejing 7 & $2017-2018$ & 2019 \\
CL5 & Dawa & Yanfeng47 & $2017-2018$ & 2019 \\
\hline
\end{tabular}

At the end of April, the soil was tilled twice by the rotary machine, and then the puddling was used one week before transplanting. The basal fertilizers were applied onto the soil surface before tillage. All plots were separated from one other and each had its own inlet and outlet to irrigate and drain water. The water regime was followed by continuous flood with 15 to $20 \mathrm{~cm}$ depth and the paddy field was dried $10 \mathrm{~d}$ before harvesting. Except that the field was irrigated with underground water in Liaozhong 
County, the water sources of other four sites were rivers. The barnyard grass and broadleaf grass were controlled by applying butachlor and bensulfuron-methyl 5 to $7 \mathrm{~d}$ after transplanting. The thiamethoxam was applied at early tillering stage to control rice borer and isoprothiolane applied $7 \mathrm{~d}$ before anthesis to control the rice blast. The pymetrozine was sprayed at filling stage to control plant hopper.

Table 2. Models set different management measures for rice in five regions in Liaoning Province

\begin{tabular}{|c|c|c|c|c|c|c|}
\hline \multirow{2}{*}{$\begin{array}{c}\text { Region } \\
\text { Cultivar }\end{array}$} & \multirow{2}{*}{ Yield level } & \multirow{2}{*}{\begin{tabular}{|c|} 
Emergence \\
Julia day
\end{tabular}} & \multirow{2}{*}{\begin{tabular}{|c|} 
Seed-bed \\
Duration (Days)
\end{tabular}} & \multicolumn{2}{|c|}{ Nitrogen Regime $\left(\mathrm{kg} \mathrm{ha}^{-1}\right)$} & \multirow{2}{*}{ Irrigation Regime } \\
\hline & & & & Amount & Ratios (TP-TL-JT) & \\
\hline & Yck & 111 & 40 & 0 & $0-0-0$ & flooded \\
\hline Dawa & Yfp & 111 & 40 & 250 & $62.5-12.5-25$ & flooded \\
\hline \multirow{2}{*}{ Yanfeng 47} & Yhh & 111 & 40 & 270 & $45-20-35$ & flooded \\
\hline & Ysh & 111 & 40 & 290 & $45-20-35$ & flooded \\
\hline \multirow{4}{*}{$\begin{array}{l}\text { Liaozhong } \\
\text { Beijing } 1\end{array}$} & Yck & 101 & 35 & 0 & $0-0-0$ & flooded \\
\hline & Yfp & 101 & 35 & 200 & $62.5-12.5-25$ & flooded \\
\hline & Yhh & 101 & 35 & 220 & $45-20-35$ & flooded \\
\hline & Ysh & 101 & 35 & 240 & $45-20-35$ & flooded \\
\hline \multirow{4}{*}{$\begin{array}{l}\text { Kaiyuan } \\
\text { Tiejing } 7\end{array}$} & Yck & 111 & 40 & 0 & $0-0-0$ & flooded \\
\hline & Yfp & 111 & 40 & 180 & $62.5-12.5-25$ & flooded \\
\hline & Yhh & 111 & 40 & 200 & $45-20-35$ & flooded \\
\hline & Ysh & 111 & 40 & 220 & $45-20-35$ & flooded \\
\hline \multirow{4}{*}{$\begin{array}{c}\text { Huanren } \\
\text { Shendao } 529\end{array}$} & Yck & 121 & 36 & 0 & $0-0-0$ & flooded \\
\hline & Yfp & 121 & 36 & 160 & $62.5-12.5-25$ & flooded \\
\hline & Yhh & 121 & 36 & 180 & $45-20-35$ & flooded \\
\hline & Ysh & 121 & 36 & 200 & $45-20-35$ & flooded \\
\hline \multirow{4}{*}{$\begin{array}{c}\text { Donggang } \\
\text { Shendao } 505\end{array}$} & Yck & 116 & 41 & 0 & $0-0-0$ & flooded \\
\hline & Yfp & 116 & 41 & 160 & $62.5-12.5-25$ & flooded \\
\hline & Yhh & 116 & 41 & 180 & $45-20-35$ & flooded \\
\hline & Ysh & 116 & 41 & 200 & $45-20-35$ & flooded \\
\hline
\end{tabular}

Note: In the nitrogen fertilizer application schedule, TP, TL, and JT represent the nitrogen application at transplanting, tillering, and jointing. For irrigation schemes, "Flooded" means using an automatic irrigation system to maintain a water depth of $10-50 \mathrm{~mm}$

The "leaf weight" method was used to measure leaf areas specifically at early growth, heading and full heading stages to obtain the leaf area index. Stem, leaf and panicle samples were taken at heading, full heading and mature stages and then dried to constant weight for measurements of dry matters. The yield was measured by threshing at the mature stage, and panicles were tested and analyzed in the laboratory. Through data extraction, we must collect important information from each trial and data records (phenological dates, leaf area index, above-ground biomass, and yield).

$$
\begin{gathered}
N_{\mathrm{f}}=\left(N_{\mathrm{y}}-N_{\mathrm{s}}\right) / E_{\mathrm{f}} \\
N_{\mathrm{y}}=\left(N_{\text {frac }} \times \text { Target Yield }\right) / \mathrm{NHI}
\end{gathered}
$$

where $N_{\mathrm{y}}$ is the above ground $\mathrm{N}$ contained in a crop with a specified yield, $N_{\mathrm{f}}$ is the $\mathrm{N}$ fertilizer requirement, $N_{\mathrm{s}}$ is the amount of $\mathrm{N}$ supplied by the soil to the above ground 
portion of the crop, $N_{\text {frac }}$ is the fraction of $\mathrm{N}$ in the grain and $\mathrm{NHI}$ is the nitrogen harvest index. The target yield is the yield we want to get in theory on a special nitrogen fertilizer amount.

Data from historical rice trials (year of 1981-2015) were collected on the agrometeorological experimental stations, including yields and dates of emergence, transplantation, flowering, and physiological maturity.

The soil data-set for this study was mainly obtained from the Environmental \& Ecological Science Data Center for West China, National Natural Science Foundation of China (http://westdc.westgis.ac.cn), and the Institute of Soil Science, Chinese Academy of Sciences (ISSCAS). The soil parameters in the model operation included the saturated water-content in different soil layers, field water-capacity, wilting-point water- content, saturated hydraulic-conductivity, bulk density (BD), texture (sand and clay content), $\mathrm{pH}$, and soil organic-matter (SOM).

The weather data in this study was obtained from the climate data-sharing service system of the China Meteorological Administration (CMA) (http://data.cma.cn) including sunshine hours $\left(\mathrm{h} ; \mathrm{h} \mathrm{d}^{-1}\right)$, maximum temperature $\left(\mathrm{TMMX} ;{ }^{\circ} \mathrm{C}\right)$, minimum temperature $\left(\mathrm{TMMN} ;{ }^{\circ} \mathrm{C}\right)$, early morning vapor pressure (VP; $\left.\mathrm{kPa}\right)$, and mean wind speed (WN; $\mathrm{ms}^{-1}$ ) (Bouman and Laar, 2001). Since solar radiation measurements were not available from the stations, the sunshine hour was converted to solar radiation using the Ångström formula (Eq.3-Eq.8) (Angstrom, 1924; Black et al., 1954).

$$
\begin{gathered}
R_{s}=R_{a} \times\left(\mathrm{a}+\mathrm{b} \times \frac{n}{N}\right) \\
R_{a}=37.59 \times d_{r} \times\left(\omega_{s} \sin \varphi \sin \delta+\cos \varphi \cos \delta \sin \omega_{\mathrm{s}}\right) \\
d_{r}=1+0.033 \times \cos \left(\frac{2 \pi}{365} J\right) \\
\delta=0.409 \times \sin \left(\frac{2 \pi}{365} J-1.39\right) \\
\omega_{S}=\arccos (-\tan \varphi \tan \delta) \\
N=\frac{24}{\pi} \omega_{s}
\end{gathered}
$$

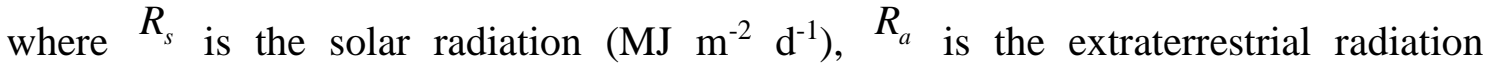
$\left(\mathrm{MJ} \mathrm{m}^{-2} \mathrm{~d}^{-1}\right), a$ and $\mathrm{b}$ are the regression constant, empirical coefficient expressing the fraction of extraterrestrial radiation reaching the earth on overcast days, $N$ is the maximum possible duration of sunshine or daylight hours(hour), $\mathrm{n}$ is the actual duration of sunshine (hour), ${ }_{r}$ is the inverse relative distance Earth-sun, $\omega_{s}$ is the sunset hour angle(rad), $\varphi$ is the latitude ( $\mathrm{rad}), \delta$ is the solar decimation (rad), $J$ is the number of the day in the year. 


\section{The ORYZA (v3) crop model}

The ORYZA model series are widely used in the world for crop growth and yield stimulation of different varieties under different environmental conditions (Belder et al., 2004; Arora, 2005; Feng et al., 2007). Leading research institutes on these models include the International Rice Research Institute (IRRI) and the University of Wageningen (WUCR) in the Netherlands (Bouman and Laar, 2001). These models can follow the daily dry-matter accumulation of plant organs and dynamically and quantitatively describe rice growth and development and yield formation of a rice crop under situations of potential production (ORYZA1), water limitations (ORYZA-W), nitrogen limitations (ORYZA-N), soil moisture and $\mathrm{N}$ dynamic changes. These models have two sub-routines (NCROP and NSOIL) to simulate the crop-soil $\mathrm{N}$ dynamics. When the experimental data file (NITROENV) was set 'NITROGEN BALANCE', NCROP and NSOIL were called by the model. NCROP is used to calculate the N demand, uptake, distribution and transport in the crop canopy and the N-restriction stress-factors. The level of $\mathrm{N}$-stress a rice plant experiences depends on the $\mathrm{N}$-availability for uptake from soil. NSOIL is used to track daily $\mathrm{N}$-availability in soil (Bouman and Laar, 2001). The models assume that the $\mathrm{N}$ is available on-demand, but actually the $\mathrm{N}$-uptake is the lower than the maximum uptake capacity of a given cultivar on the total available soil mineral N. Also a simple sub-routine (NCROP) for the calculation of the leaf $\mathrm{N}$ concentration (LNC) may allow the determination of the rice production. The ORYZA (v3) model is the latest version of the series of models, which has a stronger capability to simulate rice growth and development dynamics. In this version, N-uptake and water-uptake are coupled (Li et al., 2017). The ORYZA (v3) model adds parameters such as the critical temperature and the date of rice-growth for better controls on the plant growth. Additional features are added for large-scale simulation, automatic parameter adjustment, carbon and nitrogen cycle, and the impact of greenhouse gases on climate change. Meanwhile, the soil-nutrient-content and irrigation-measure settings have been improved to increase the accuracy of simulating rice physiological processes, irrigation management measures, and dynamic changes of soil moisture (Guo et al., 2017).

\section{Model calibration and validation}

In this study, we selected a representative cultivar from each region to specify crop coefficients using ORYZA (v3) calibration. To evaluate model performance, we split the experimental data into two parts: training and validation data sets (Table 1). Previous empirical researches have convincingly showed that most crop-specific parameters are generic (Bouman and Laar, 2001; Li et al., 2017). Therefore, the bulk of our model parameters were taken from IR72 and were not adjusted during model identification. However, several parameters such as development rates, partitioning factors, relative leaf growth rate, specific leaf area, and the fraction of stem reserves (about $10 \%$ in the ORYZA (v3) model) needed to be adjusted specifically for the variety and environment to obtain an optimal model. Consistent with previous studies, we used DRATES and PARAM to determine development rates and other parameters (Kropff et al., 1994). Then we validated, trained, and improved the ORYZA (v3) model parameters in a trial and error process until the satisfactory performance achieved. Thereafter, one out-of-sample test by applying the calibrated model was performed to confirm the validation of the model. 
The crop model calibration approach consists of three stages: 1) calculating the mean absolute difference $\left(\mathrm{d}_{\mathrm{a}}\right)(E q .9)$ between the observed and the simulated values. The $\mathrm{d}_{\mathrm{a}}$ is defined as an index that measures the average magnitude of errors in a set of forecasts and accuracy for continuous variables (Cao et al., 2006). It should be a pre-condition for validation of the ORYZA (v3) model; 2) calculating the root mean square errors (RMSE) (Eq.10) and normalized root mean square error (NRMSE) (Eq.11), which are defined as a quadratic scoring rule that measures the average magnitude of the error (Stockle et al., 1994; Evers et al., 2005); 3) measuring the intercept $(\alpha)$, slope $(\beta)$, and coefficient of determination $\left(\mathrm{R}^{2}\right)$, at the same time plotting 1:1 diagram. The Model validation is mainly based on plotting comparison of theory and field measurement, including the weights of leaves (WLVG; $\mathrm{kg} \mathrm{ha}^{-1}$ ), stems (WST; $\mathrm{kg} \mathrm{ha}^{-1}$ ), storage organs (WSO; $\mathrm{kg} \mathrm{ha}^{-1}$ ), leaf area index (LAI), and grain yield. In this study, a student t-test was used to test differences in quantitative data among different groups. Ideally, the statistical parameters values of $\beta, \mathrm{R}^{2}$ should be close to 1 . Data were analyzed by spss6.0 using Student t-test $\left(\mathrm{P}\left(\mathrm{t}^{*}\right)\right)$ and results were considered significant when $\mathrm{p}<0.05$. Excel 2019 and Origin 2018 were the main tools for analyzing data and drawing figures.

$$
\begin{gathered}
d_{a}=\frac{1}{n} \sum_{i=1}^{n}\left(Y_{i}-X_{i}\right) \\
R M S E=\sqrt{\frac{1}{n} \sum_{i=1}^{n}\left(Y_{i}-X_{i}\right)^{2}} \\
\text { NRMSE }=100 \frac{\sqrt{\sum_{i=1}^{n}\left(Y_{i}-X_{i}\right)^{2} / n}}{\bar{x}}
\end{gathered}
$$

where $n$ is the number of samples, and $Y_{i}$ and $X_{i}$ represent the simulated and measured values. The root mean square error ( $R M S E$ ) and the normalized root mean square error ( NRMSE) reflect the magnitude of the simulated error. The mean of the values reflects the overall simulation effect. NRMSE $<15 \%, 15 \% \leq N R M S E<30 \%$ and $N R M S E>30 \%$ indicate that the model simulation residuals are small, medium and large (Gaiser et al., 2010; Liu et al., 2011).

\section{Scenario analyses}

Validated ORYZA (v3) model was used to simulate the grain yield of rice concerning four critical $\mathrm{N}$-fertilizer management practices employing weather data of Liaoning province from 1981 to 2015 (CMA). In scenario analyses, model runs with different emergence day (EMD) of the five stations were set as the $111^{\text {th }}$ day (Dawa), $101^{\text {th }}$ day (Liaozhong), $111^{\text {th }}$ day (Kaiyuan), $121^{\text {th }}$ day (Huanren), $116^{\text {th }}$ day (Donggang) of the year. The settings of other management practices were the same with those for the field experiments (Table 2). The simulation continued until plant-death or the physiological mature-stage. 


\section{Results}

\section{Calibration and validation of ORYZA (v3)}

\section{Determination of model parameters}

The life cycle of the rice crop can be divided into four main phenological phases: the basic vegetative phase (BVP), photoperiod-sensitive phase (PSP), panicle formation phase (PFP), and grain-filling phase (GFP). The corresponding development-rate constants are development-rate in the juvenile phase (DVRJ), development-rate in photoperiod-sensitive phase (DVRI), development-rate in panicle development (DVRP), development-rate in the reproductive phase (DVRR). Adjusted model development parameters were listed in Table 3. Table 4 showed the distribution of assimilation distribution coefficients and specific leaf-area parameters describing that the total daily dry-matter increment was partitioned to the various plant organ groups according to fractions which were a function of the development stage (Bouman and Laar, 2001). It was reflecting a rather high degree of regional specificity.

Table 3. Corrected values of rice development rate in five test sites in Liaoning Province

\begin{tabular}{c|c|c|c|c|c}
\hline $\begin{array}{c}\text { Development } \\
\text { stage }\end{array}$ & $\begin{array}{c}\text { Huanren } \\
\text { Shendao 529 }\end{array}$ & $\begin{array}{c}\text { Donggang } \\
\text { Shendao 505 }\end{array}$ & $\begin{array}{c}\text { Liaoning } \\
\text { Beijing 1 }\end{array}$ & $\begin{array}{c}\text { Kaiyuan } \\
\text { Tiejing 7 }\end{array}$ & $\begin{array}{c}\text { Dawa } \\
\text { Yanfeng 47 }\end{array}$ \\
\hline DVRJ & 0.0007932 & 0.0008890 & 0.0008969 & 0.0007960 & 0.0008860 \\
DVRI & 0.0008976 & 0.0008076 & 0.0007696 & 0.0008976 & 0.0007576 \\
DVRP & 0.0004741 & 0.0005630 & 0.0008544 & 0.0005990 & 0.0005420 \\
DVRR & 0.0019309 & 0.0016590 & 0.0019500 & 0.0016710 & 0.0013030 \\
\hline
\end{tabular}

\section{Calibration and validation of the model}

The comparison of simulated and observed "key phenology days after transplantation" was showed in Table 5. The relative errors between the simulated value and measured value were 0-3 d for the flowering stage, and the average simulation error was about $2 \mathrm{~d}$. The relative simulation error for the mature period was $0-5 \mathrm{~d}$, and the average simulation error was about $2.5 \mathrm{~d}$. Furthermore, according to the linear regression analysis, the coefficient of determination $\left(\mathrm{R}^{2}\right)$ was between 0.96 to 0.98 (Table 6). Thus, the measured values of the growth period showed a good agreement with the simulated values.

Leaf area index (LAI) is widely used to measure the growth of plants. Graphical comparisons of simulated and measured LAI over time were provided in Figure 2 $(a 2-e 2)$. Although we observed LAI variation in different areas, there was a satisfactory agreement between simulated and measured LAIs. The root mean square error and $\mathrm{R}^{2}$ were $9 \%$ and 0.93 , respectively, and there was no significance by a t-test. The testing of the model indicated that the model could well simulate the change in the dynamics of LAI.

In the calibration stage of 2017 ( I ), the simulated values of above-ground biomass revealed a statistically acceptable level of agreement with their observed values (Figure 2 (al-e1)). The statistical analysis result showed that there was no significant difference between measured and observed above-ground biomass values ( $\mathrm{p}=0.37$ to 0.50 , t-test), linear regression coefficients ranging from 0.79 to 0.96 , and that the intercept was greater than zero possibly due to the higher estimation of rice growth by 
the model in the early growth stage. The normalized root mean square errors (NRMSE) of WST, WLVG, WSO were 10\%, 24\%, and 12\%, respectively. Generally, in comparison with the 5 experiment sites observed in 2019 (II), the model simulation was well performed. As shown in Table 5, the results of the t-test were ranged from 0.44 to 0.48 (no significance difference), the linear regression coefficient awas close to 1 , and the regression equation was significant $\left(\mathrm{R}^{2}\right.$ was 0.95 to 0.96$)$. Both the simulated and measured above-ground biomass errors were under a reasonable range, which proved that the model was performing well.

Table 4. Corrected values of assimilation distribution coefficient and specific leaf area parameters in five test sites in Liaoning Province

\begin{tabular}{|c|c|c|c|c|c|c|}
\hline \multirow{2}{*}{ Location } & \multicolumn{4}{|c|}{ Assimilation coefficient } & \multicolumn{2}{|c|}{ Specific leaf area } \\
\hline & DVS & FSTTB & FLVTB & FSOTB & DVS & SLA \\
\hline \multirow{5}{*}{ Huanren } & 0.00 & 0.60 & 0.40 & 0.00 & 0.16 & 0.0055 \\
\hline & 0.50 & 0.60 & 0.40 & 0.00 & 0.33 & 0.0040 \\
\hline & 0.75 & 0.85 & 0.05 & 0.10 & 0.65 & 0.0028 \\
\hline & 1.00 & 0.11 & 0.00 & 0.89 & 0.79 & 0.0025 \\
\hline & 1.20 & 0.00 & 0.00 & 1.00 & 2.10 & 0.0025 \\
\hline \multirow{5}{*}{ Donggang } & 0.00 & 0.31 & 0.69 & 0.00 & 0.16 & 0.0036 \\
\hline & 0.50 & 0.33 & 0.67 & 0.00 & 0.33 & 0.0035 \\
\hline & 0.75 & 0.55 & 0.15 & 0.3 & 0.65 & 0.0033 \\
\hline & 1.00 & 0.02 & 0.00 & 0.98 & 0.79 & 0.0032 \\
\hline & 1.20 & 0.00 & 0.00 & 1.00 & 2.10 & 0.0024 \\
\hline \multirow{5}{*}{ Liaozhong } & 0.00 & 0.42 & 0.58 & 0.00 & 0.16 & 0.0054 \\
\hline & 0.50 & 0.43 & 0.57 & 0.00 & 0.33 & 0.0047 \\
\hline & 0.75 & 0.65 & 0.25 & 0.10 & 0.65 & 0.0038 \\
\hline & 1.00 & 0.085 & 0.00 & 0.915 & 0.79 & 0.0038 \\
\hline & 1.20 & 0.00 & 0.00 & 1.00 & 2.10 & 0.0026 \\
\hline \multirow{5}{*}{ Kaiyuan } & 0.00 & 0.31 & 0.69 & 0.00 & 0.16 & 0.0040 \\
\hline & 0.50 & 0.33 & 0.67 & 0.00 & 0.33 & 0.0035 \\
\hline & 0.75 & 0.55 & 0.15 & 0.30 & 0.65 & 0.0033 \\
\hline & 1.00 & 0.02 & 0.00 & 0.98 & 0.79 & 0.0032 \\
\hline & 1.20 & 0.00 & 0.00 & 1.00 & 2.10 & 0.0024 \\
\hline \multirow{5}{*}{ Dawa } & 0.00 & 0.62 & 0.38 & 0.00 & 0.16 & 0.0045 \\
\hline & 0.50 & 0.62 & 0.38 & 0.00 & 0.33 & 0.0030 \\
\hline & 0.75 & 0.85 & 0.05 & 0.10 & 0.65 & 0.0026 \\
\hline & 1.00 & 0.11 & 0.00 & 0.89 & 0.79 & 0.0026 \\
\hline & 1.20 & 0.00 & 0.00 & 1.00 & 2.10 & 0.0023 \\
\hline
\end{tabular}

NOTE: Table of the fraction of shoot dry matter partitioned to the leaves (FLVTB), Table of the fraction of shoot dry matter partitioned to the stems (FSTTB), Table of the fraction of shoot dry matter partitioned to the panicles (FSOTB). Emergence stage (DVS $=0.00$ ), panicle initiation stage (DVS = $0.65)$, flowering stage (DVS $=1.00)$, and physiological maturity stage $(\mathrm{DVS}=2.00)$

The simulated and measured results of yield were illustrated in Figure 3 with a great agreement. In the calibration stage ( I ), the resulting values were distributed around 1:1 lined (b). According to the statistical analysis (Table 6), the linear regression coefficients $\alpha$ was 1.08 (proximity near one), the intercept $\beta$ of the linear regression through the data was -806 , which indicated that the model underestimated the yield of 
rice. In the calibration stage (II), the points got much closer to the 1:1 line distribution (a). And the model had a higher coefficient of determination $\left(\mathrm{R}^{2}\right)$ and NRMSE was $4 \%$. In addition, there were no significant differences as determined by Student's t-test (Table 7). These values were considered to be within acceptable limits.

Table 5. Comparison between simulated and measured values of the key phenology days

\begin{tabular}{|c|c|c|c|c|c|c|c|c|c|c|c|c|}
\hline \multirow{3}{*}{ Location } & \multicolumn{4}{|c|}{ Flowering } & \multicolumn{4}{|c|}{ Maturity } & \multicolumn{2}{|c|}{ Flowering } & \multicolumn{2}{|c|}{ Maturity } \\
\hline & \multicolumn{2}{|c|}{$\begin{array}{c}\text { Simulated } \\
\text { value }\end{array}$} & \multicolumn{2}{|c|}{ Observed value } & \multicolumn{2}{|c|}{$\begin{array}{l}\text { Simulated } \\
\text { value }\end{array}$} & \multicolumn{2}{|c|}{ Observed value } & \multicolumn{4}{|c|}{$\begin{array}{l}\text { Difference between simulation } \\
\text { and observation }\end{array}$} \\
\hline & 2017 & 2018 & 2017 & 2018 & 2017 & 2018 & 2017 & 2018 & 2017 & 2018 & 2017 & 2018 \\
\hline Huanren & 78 & 77 & 76 & 75 & 128 & 125 & 129 & 127 & 2 & 2 & 1 & 2 \\
\hline Donggang & 76 & 78 & 75 & 75 & 148 & 146 & 145 & 144 & 1 & 3 & 3 & 2 \\
\hline Liaozhong & 90 & 88 & 91 & 90 & 146 & 146 & 148 & 149 & 1 & 2 & 2 & 3 \\
\hline Kaiyuan & 77 & 76 & 78 & 77 & 131 & 130 & 133 & 133 & 1 & 1 & 2 & 3 \\
\hline Dawa & 80 & 78 & 78 & 75 & 150 & 152 & 155 & 156 & 2 & 3 & 5 & 4 \\
\hline
\end{tabular}

Table 6. The statistical test results on the calibration data set ( I), including LAI, biomass, and yield

\begin{tabular}{|c|c|c|c|c|c|c|c|c|c|c|c|c|}
\hline \multirow[b]{2}{*}{ Year } & \multirow[b]{2}{*}{ Crop variable } & \multirow[b]{2}{*}{$\mathbf{N}$} & \multirow[b]{2}{*}{$X_{\text {obs }}$} & \multirow[b]{2}{*}{ SD Xobs } & \multirow[b]{2}{*}{$X_{\text {sim }}$} & \multirow{2}{*}{ SD Xsim } & \multirow[b]{2}{*}{$\mathbf{P}\left(\mathbf{t}^{*}\right)$} & \multirow[b]{2}{*}{ a } & \multirow[b]{2}{*}{ b } & \multirow{2}{*}{$\mathbf{R}^{2}$} & \multirow{2}{*}{\begin{tabular}{|l|} 
RMSE \\
absolute
\end{tabular}} & \multirow{2}{*}{\begin{tabular}{|l} 
RMSE (\%) \\
normalized
\end{tabular}} \\
\hline & & & & & & & & & & & & \\
\hline \multirow{6}{*}{2017} & $\begin{array}{c}\text { The key } \\
\text { phenology days } \\
\text { (d) }\end{array}$ & 10 & 110.4 & 32.78 & 110.8 & 33.94 & 0.49 & 0.96 & 3.59 & 0.98 & 1.8 & 1.62 \\
\hline & $\begin{array}{c}\text { Biomass of green } \\
\text { leaves }\left(\mathrm{kg} \mathrm{ha}^{-1}\right)\end{array}$ & 16 & 1058 & 2095 & 2220 & 1165 & 0.37 & 0.810 & 555 & 0.79 & 528 & 24 \\
\hline & $\begin{array}{c}\text { Biomass of stems } \\
\left(\mathrm{kg} \mathrm{ha}^{-1}\right)\end{array}$ & 16 & 4429 & 2631 & 4627 & 2638 & 0.42 & 0.970 & -136 & 0.96 & 446 & 10 \\
\hline & $\begin{array}{l}\text { Biomass of } \\
\text { panicles } \\
\left(\mathrm{kg} \mathrm{ha}^{-1}\right)\end{array}$ & 16 & 3972 & 4195 & 4086 & 4241 & 0.47 & 0.940 & -43 & 0.95 & 477 & 12 \\
\hline & $\begin{array}{c}\text { Leaf Area Index } \\
(-)\end{array}$ & 16 & 3.33 & 0.77 & 4.96 & 2.56 & 0.45 & 0.910 & -0.55 & 0.93 & 0.49 & 9 \\
\hline & Yield $\left(\mathrm{kg} \mathrm{ha}^{-1}\right)$ & 20 & 8914 & 2317 & 8980 & 2079 & 0.46 & 1.080 & -806 & 0.94 & 400 & 4 \\
\hline \multirow{6}{*}{2018} & $\begin{array}{c}\text { The key } \\
\text { phenology days (d) }\end{array}$ & 10 & 109.6 & 32.92 & 110.1 & 34.6 & 0.49 & 0.95 & 5.04 & 0.97 & 2.43 & 2.2 \\
\hline & $\begin{array}{l}\text { Biomass of green } \\
\text { leaves }\left(\mathrm{kg} \mathrm{ha}^{-1}\right)\end{array}$ & $\mid 16$ & 2249 & 891 & 2284 & 891 & 0.46 & 1.040 & -124 & 0.88 & 75 & 9 \\
\hline & $\begin{array}{c}\text { Biomass of stems } \\
\left(\mathrm{kg} \mathrm{ha}^{-1}\right)\end{array}$ & $\mid 16$ & 7286 & 2079 & 7288 & 2152 & 0.50 & 0.960 & 268 & 0.96 & 104 & 2 \\
\hline & $\begin{array}{c}\text { Biomass of } \\
\text { panicles }\left(\mathrm{kg} \mathrm{ha}^{-1}\right)\end{array}$ & & 3885 & 2834 & 4939 & 3858 & 0.44 & 0.960 & 16 & 0.94 & 69 & 4 \\
\hline & $\begin{array}{c}\text { Leaf Area Index } \\
(-)\end{array}$ & 16 & 5.43 & 2.22 & 5.39 & 2.65 & 0.48 & 0.805 & 1.10 & 0.93 & 0.48 & 9 \\
\hline & Yield $\left(\mathrm{kg} \mathrm{ha}^{-1}\right)$ & & 8358 & 2675 & 8504 & 2559 & 0.43 & 1.020 & -337 & 0.96 & 565 & 7 \\
\hline
\end{tabular}




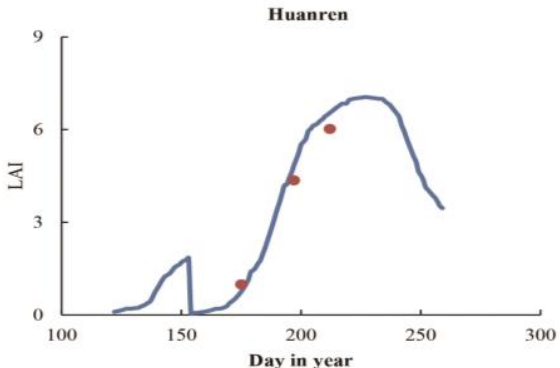

(a1)

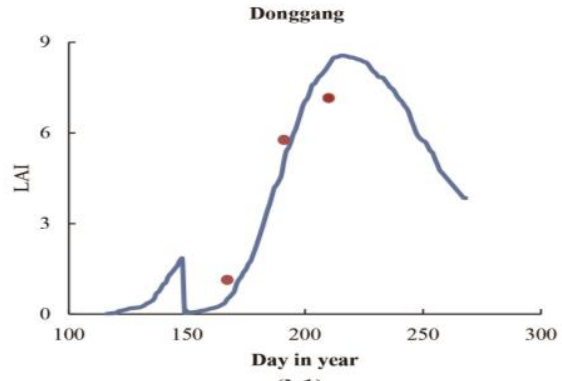

(b1)

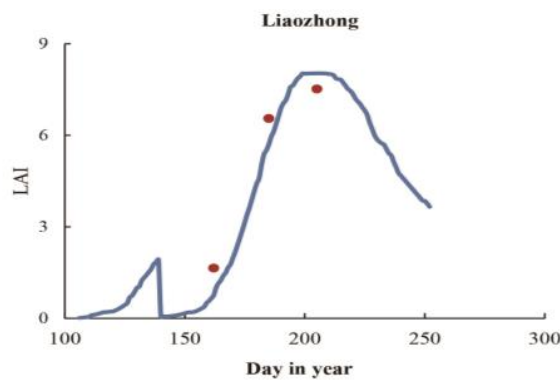

(c1)

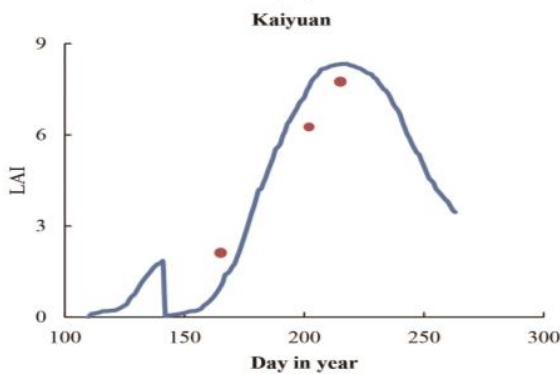

(d1)

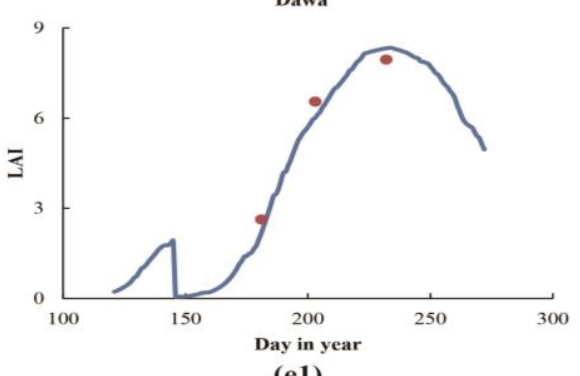

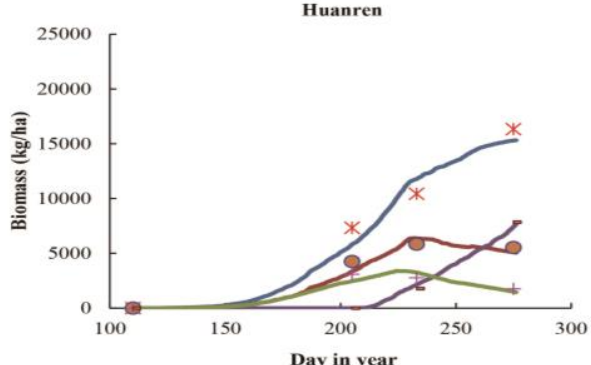

(a2)

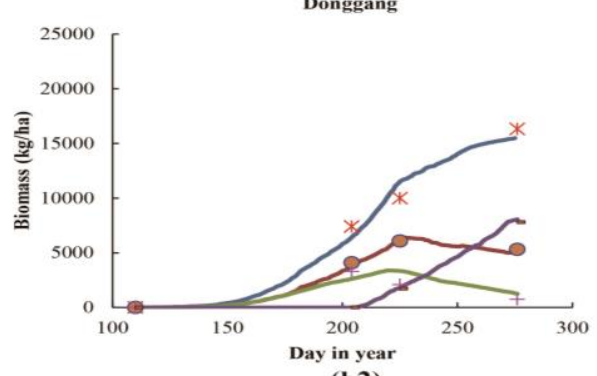

(b2)

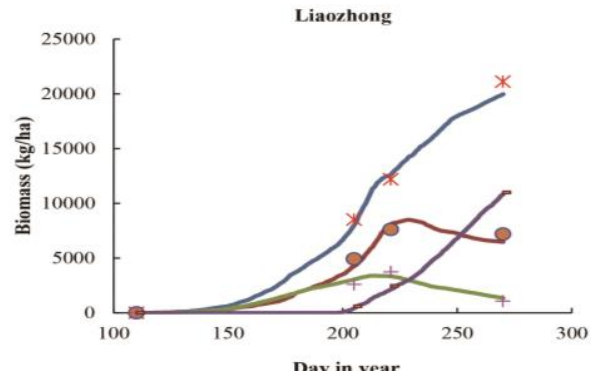

(c2)

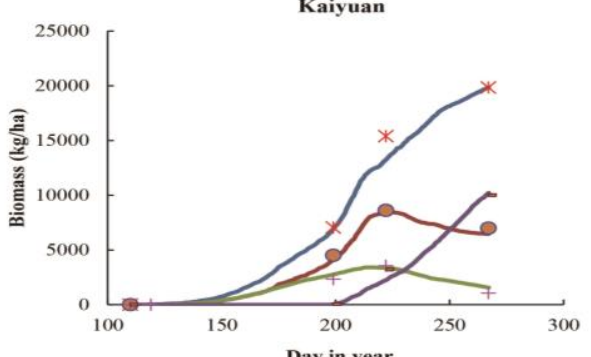

(d2)
(d2)

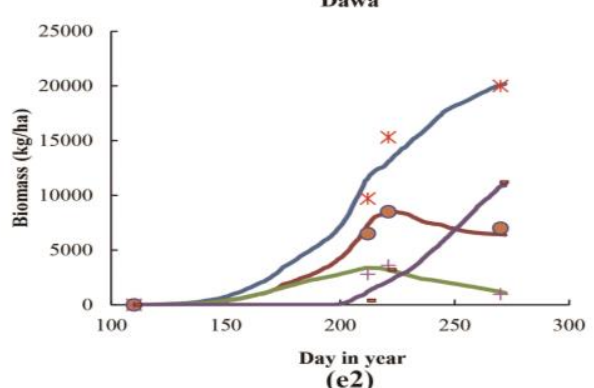

Figure 2. Simulated (lines) and measured biomass of the whole crop (K), green leaves $(+)$, stems (•), and panicles (-), and leaf area index (LAI) of rice in Huanren (a), Donggang (b), Liaozhong (c), Kaiyuan (d), Dawa (e), farmers' yield level $N$ applied in 2017(calibration data 


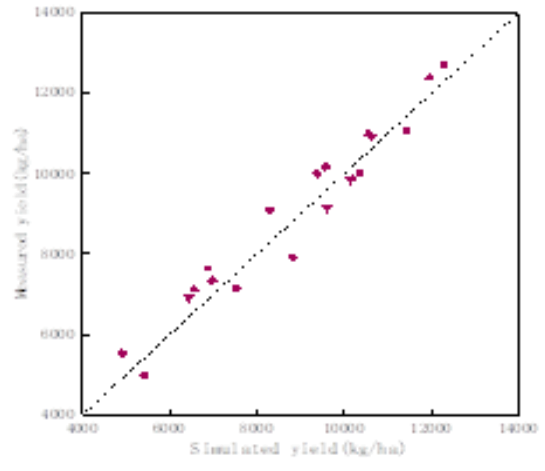

(a)

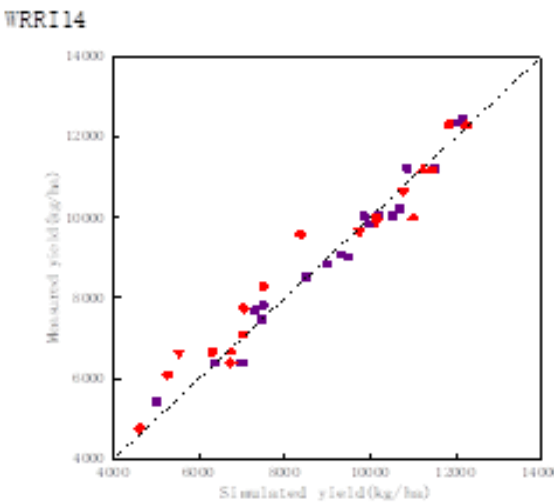

(b)

Figure 3. Comparison between simulated and measured values of grain yield in rice at the regional scale using the ORYZA (v3) models. Subplots (a) and (b) represent the validation stage and the calibration stage value, respectively

Table 7. The statistical test results on the validation dataset (II), including LAI, biomass, and yield

\begin{tabular}{|c|c|c|c|c|c|c|c|c|c|c|c|c|}
\hline \multirow{2}{*}{ Year } & \multirow{2}{*}{ Crop variable } & \multirow[b]{2}{*}{$\mathbf{N}$} & \multirow{2}{*}{$X_{\text {obs }}$} & \multirow{2}{*}{ SD Xobs } & \multirow{2}{*}{$X_{\text {sim }}$} & \multirow{2}{*}{ SD Xsim } & \multirow{2}{*}{$\mathbf{P}\left(\mathbf{t}^{*}\right)$} & \multirow[b]{2}{*}{ a } & \multirow{2}{*}{ b } & \multirow{2}{*}{$\mathbf{R}^{2}$} & \multirow{2}{*}{\begin{tabular}{|l|} 
RMSE \\
absolute
\end{tabular}} & \multirow{2}{*}{\begin{tabular}{|l} 
RMSE (\%) \\
normalized
\end{tabular}} \\
\hline & & & & & & & & & & & & \\
\hline \multirow{6}{*}{2019} & $\begin{array}{c}\text { The key } \\
\text { phenology } \\
\text { days }(\mathrm{d})\end{array}$ & 10 & 108.9 & 33.61 & 110.1 & 34.6 & 0.47 & 0.97 & 2.34 & 0.96 & 3.21 & 2.92 \\
\hline & $\begin{array}{c}\text { Biomass of green } \\
\text { leaves }\left(\mathrm{kg} \mathrm{ha}^{-1}\right)\end{array}$ & 16 & 1907 & 1626 & 1961 & 1691 & 0.44 & 0.930 & 61 & 0.96 & 349 & 18 \\
\hline & $\begin{array}{l}\text { Biomass of stems } \\
\quad\left(\mathrm{kg} \mathrm{ha}^{-1}\right)\end{array}$ & 16 & 5422 & 4213 & 5470 & 4245 & 0.48 & 0.950 & 91 & 0.96 & 798 & 15 \\
\hline & $\begin{array}{c}\text { Biomass of } \\
\text { panicles }\left(\mathrm{kg} \mathrm{ha}^{-1}\right)\end{array}$ & 16 & 1926 & 1496 & 1969 & 1546 & 0.47 & 0.930 & 69 & 0.95 & 244 & 12 \\
\hline & $\begin{array}{c}\text { Leaf Area Index } \\
(-)\end{array}$ & 16 & 5.49 & 2.46 & 5.39 & 2.57 & 0.46 & 0.890 & 0.57 & 0.90 & 0.49 & 9 \\
\hline & Yield $\left(\mathrm{kg} \mathrm{ha}^{-1}\right)$ & 20 & 8514 & 2868 & 8999 & 2110 & 0.45 & 1.010 & -729 & 0.95 & 328 & 4 \\
\hline
\end{tabular}

\section{Scenario analyses}

The calibrated and validated ORYZA (v3) model was applied to predict growth and production in rice, using weather data from 1981 to 2015 . The cumulative probability distribution of grain-yield in five rice-growing areas under different $\mathrm{N}$ fertilizer management were shown in Figure $4(a-d)$. ORYZA (v3) simulated similar trend of grain-yields trends in different rice-growing areas showing that higher grain-yields with increasing $\mathrm{N}$ fertilization as $\mathrm{Ysh}>\mathrm{Yhh}>\mathrm{Yfp}>$ Yck. Among compared growing-areas, the yield differences across years were larger with a high $\mathrm{N}$ rate. The lowest yield was obtained at CL2 under the Yck level, and the median (with 50\% probability of exceedance) of simulated grain yield was $4500 \mathrm{~kg} \mathrm{ha}^{-1}$. In addition, in the CL1 area which lacked thermal resources the simulated data had a lower value with Yfp to Ysh levels. From the Yfp to Ysh level, the median (with 50\% probability of exceedance) of 
simulated grain yields were $6500 \mathrm{~kg} \mathrm{ha}^{-1}, 7500 \mathrm{~kg} \mathrm{ha}^{-1}, 8750 \mathrm{~kg} \mathrm{ha}^{-1}$, respectively. On the contrary, in CL5 where the region of adequate thermal resources, all four yield levels were expressed at higher values. From the Yck to the Ysh level, the median of simulated grain yield was $6700 \mathrm{~kg} \mathrm{ha}^{-1}, 9600 \mathrm{~kg} \mathrm{ha}^{-1}, 10500 \mathrm{~kg} \mathrm{ha}^{-1}, 11700 \mathrm{~kg} \mathrm{ha}^{-1}$, respectively. The difference in simulated yields in different areas over the years was mainly attributed by differences in temperature and solar radiation, and high $\mathrm{N}$ rates enhanced the variation.

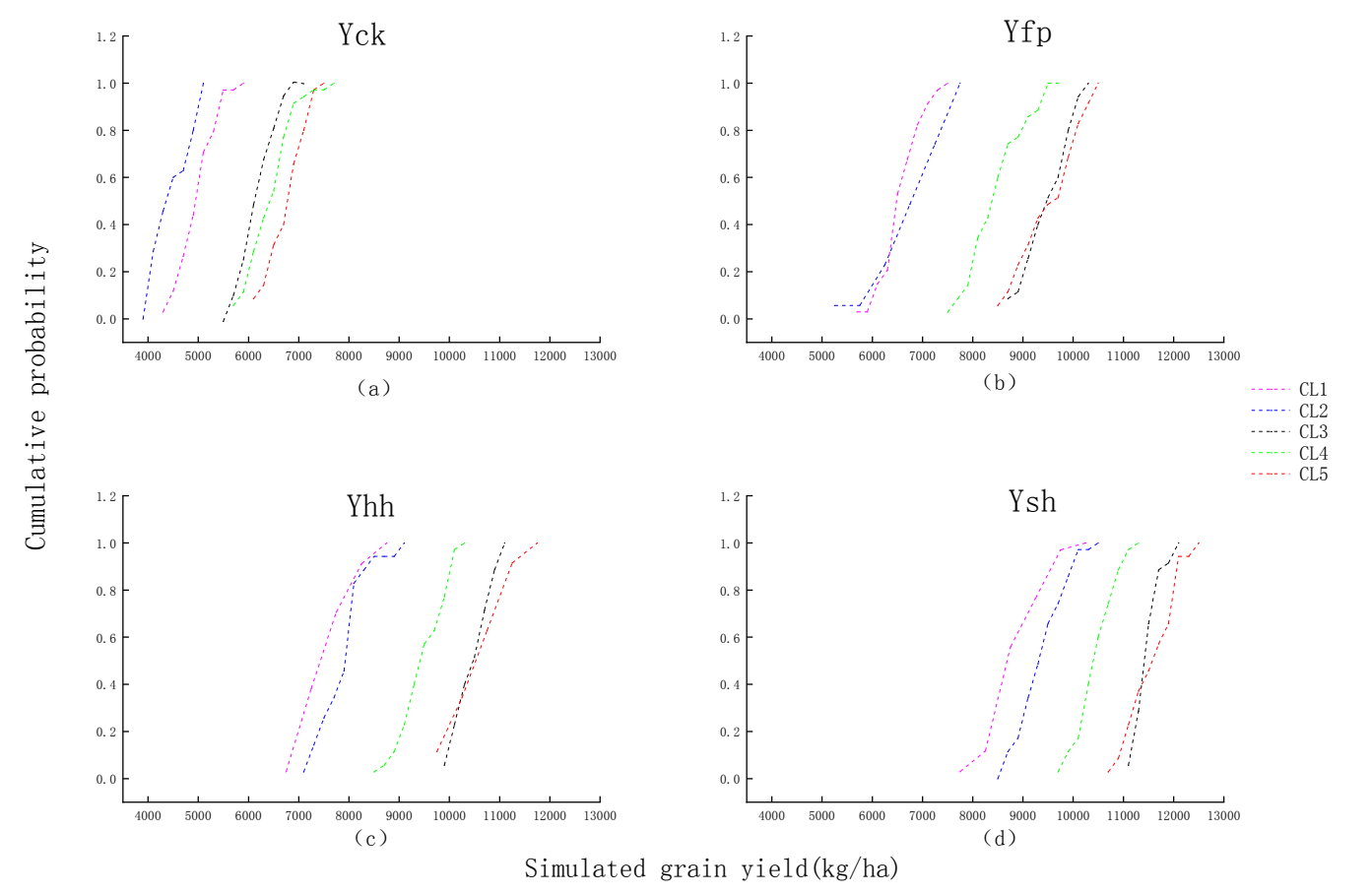

Figure 4. Cumulative probability distribution curves of simulated grain yield from 1981 to 2015 under four $N$ application

Figure 5 (a-e) showed the detailed changes of simulated grain yield from 1981 to 2015. Spatial distribution characteristics could be obviously identified in different regions. The average simulated grain-yield over 35 years under four $\mathrm{N}$ fertilizers application were also exhibited in Figure $5(f)$. The yields at four levels in CL1 and CL2 regions were generally lower than those in CL3-CL5 regions. However, regardless of the regions, $\mathrm{N}$ significantly increased the grain-yields. From the N-level perspective, different fertilizer levels showed different influences on the rice yield. From the Figure 5 that, the increase of yield was significant from Yck to Yfp with a lower $\mathrm{N}$ level. The increase of yield was also significant in CL3 and CL5 regions but relatively small in CL1 region. For Yhh and Ysh levels, an increasing trend in yield was identified with increasing $\mathrm{N}$ applied. As $\mathrm{N}$ fertilizer continued increasing, the increase of yield trend had obviously slowed down which was indicated by the slope of the increase. With high $\mathrm{N}$ levels, the grain-yield increase in the CL1 region was large while that in the CL4 regions were relatively small. The grain-yield increased from Yhh to Ysh in CL1 to CL5 were $747 \mathrm{~kg} \mathrm{ha}^{-1}, 795 \mathrm{~kg} \mathrm{ha}^{-1}, 705 \mathrm{~kg} \mathrm{ha}^{-1}, 252 \mathrm{~kg} \mathrm{ha}^{-1}, 643 \mathrm{~kg} \mathrm{ha}^{-1}$, respectively. Therefore, scenario analyses suggested that $\mathrm{N}$ fertilization posted great effects on the rice yield, especially with the low $\mathrm{N}$ level. Also the response of rice yield 
to $\mathrm{N}$ application declined with an increase in the $\mathrm{N}$ application rate to the level of Yhh. The five regions showed significant differences in rice yield and the application of $\mathrm{N}$ fertilizer increased the regional differences.
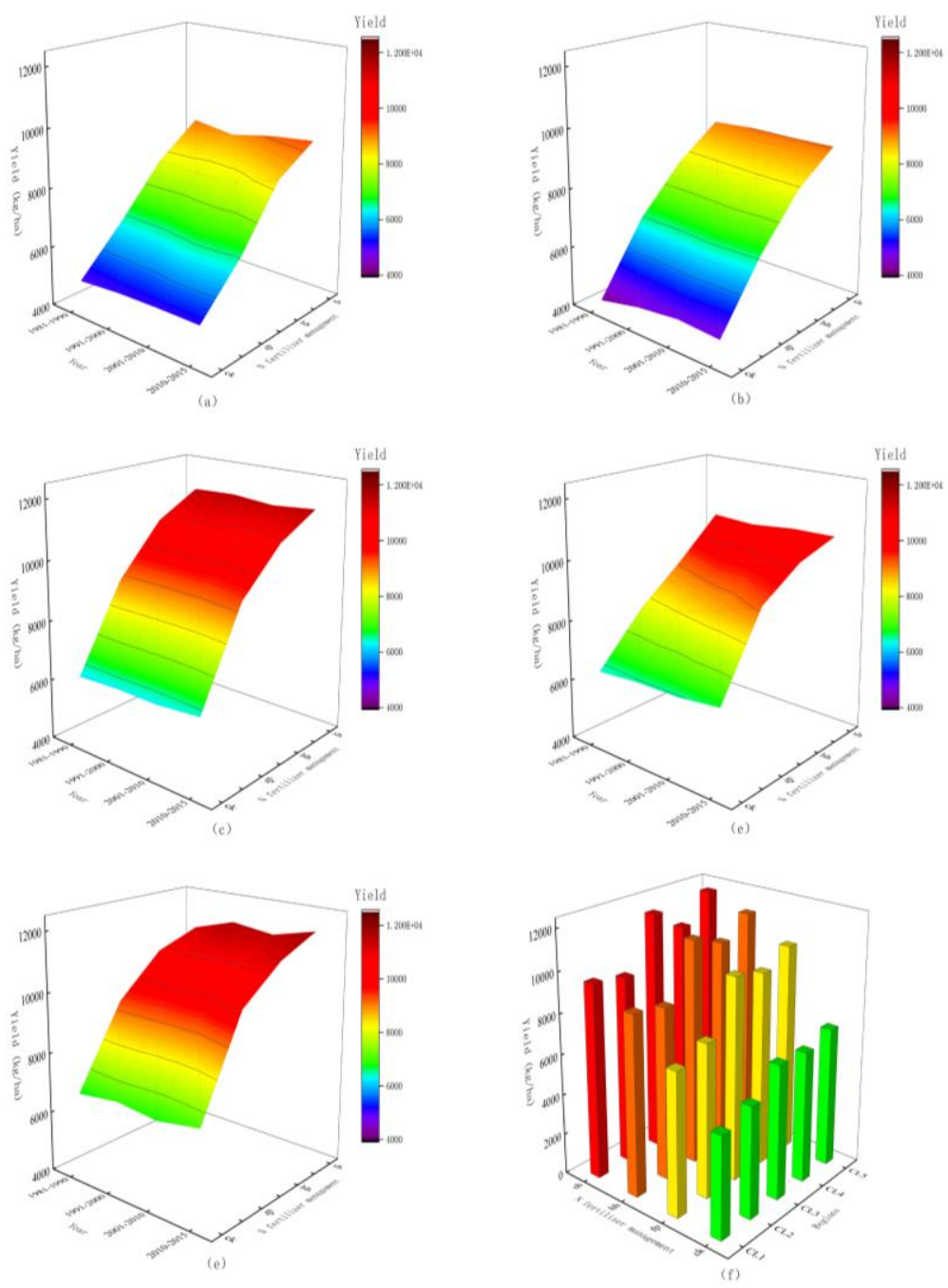

Figure 5. Simulated yield change (1981-2015) in different levels for five regions, respectively $(a-e)$, meanwhile, shows the average simulated yield in different regions of 35 years under four $N$ fertilizer management $(f)$

\section{Discussion}

In this study, we integrated examined field test data to study localized and regionalized of the ORYZA (v3) model and obtained the parameters of growth and development in different regions in Liaoning province, which were clearly distinguished from its cultivar parameters (IR72). The model evaluation was an important procedure before the model application. By comparing with the experimental data of the key phenology days in five regions, it was verified that the error of simulation data was less than $5 \mathrm{~d}$. Additionally, the value passed the test of significance, which also proved the rationality of the model. The statistical parameters and scatter diagrams showed a relatively close agreement between measured and simulated biomass in the calibration 
data set ( I ) and validation data set ( II ). The other parameter was NRMSE in which the predicted value was relatively deviated from the real value. The lower value of NRMSE indicated a better precision and reliability of the simulation-performance, while a higher NRMSE value indicated a poor performance (Confalonieri et al., 2016). The NRMSE of WLVG, WST, and WSO in 2017-2019 were 9\%-24\%, 2\%-15\%, and 4\%-12\%, respectively. The simulation results also showed that the simulated values of WSO and WST performed better than the value of WLVG, and an acceptable coefficient of determination $\left(R^{2}\right)$ values was obtained in all cases $\left(R^{2}>0.9\right)$. Besides, simulated grainyields were also in agreement with observation from five regions in Liaoning province. Its $\mathrm{R}^{2}$ ranged from 0.95 to 0.96 and the $\alpha$ was close to 1 . Nevertheless, for simulated LAI, the effect was not better than other indexes, which was consistent with previous studies (Bouman and Laar, 2004; Li et al., 2017). This might result from the calculation method of the model which calculates leaf area (LA) with a specific leaf area (SLA). This calculation method involved some disadvantages, including the lack of mechanistic explanations of the environmental-factors and management-measures influences, which could lead to certain errors between the simulated and the measured values. In general, these simulation results were in good qualitative agreement with experimental observations in Liaoning province. It also provided a basis for further applications of the model to resource-utilization analysis and climate-change-impact researches.

Scenario analyses indicated that $\mathrm{N}$ fertilizer application method could significantly influence grain-yields and the $\mathrm{N}$ fertilizer requirement varied with the yield level. The yield increased with an increase in the amount of $\mathrm{N}$ fertilizer applied as shown by Ysh>Yhh>Yfp>Yck. No matter in which area, the changes in Yfp to Yhh were all greater than the changes in Yhh to Ysh since the extent of the grain-yield increase decreased as the $\mathrm{N}$ fertilizer increased. This finding was consistent with results from previous researches (Wang et al., 2010; York et al., 2016; Wang, 2017). Several studies have shown that the reason that fertilizer usage does not guarantee a higher yield is because of declining returns (Shen et al., 1994; Liu et al., 2000; Chen et al., 2011), which is also consistent with our conclusion in this paper. Excessive fertilization not only leads to a decrease in $\mathrm{N}$ utilization-efficiency but also causes a series of adverse environmental reactions (Mao et al., 2005). However, it was found that $\mathrm{N}$ fertilization showed different influences on grain-yields in different growing-zones. With the $\mathrm{N}$ fertilizer increase, the grain-yield increased significantly in the central plain, northern plain and Liaohe Delta rice planting area. This was because of the good thermal resource and sufficient solar radiation in the growing season in these rice planting regions. The improvement of rice grain-yield and $\mathrm{N}$ use-efficiency depended on the good weather conditions. At higher $\mathrm{N}$ fertilizer levels, lower gains were observed in the eastern hilly area and the coastal plain. The eastern hilly area is a cold region with fewer heat resources during the growing season, where the availability of $\mathrm{N}$ fertilizers is frequently limiting. On the other hand, although there are enough heat resources, there are problems such as excessive precipitation and insufficient sunshine in the coastal plain. These issues in a way would be prone to cause lodging, plant diseases and insect pests with higher $\mathrm{N}$ fertilizer level. So, only by jointing efforts of breeding new resistant cultivars, changing the irrigation patterns, and reducing fertilizer $\mathrm{N}$ input we could improve the yield in these coastal plains (Chen et al., 2019). Nitrogen use-efficiency has not been calculated in this paper, and future research needs to carry out correlation analysis in this aspect to better study the relationship between nitrogen fertilizer and yield. 
On the regional-scale level, our simulation results fitted well with the experimental results, which indicated that the model was suitable for Liaoning province. However, this paper did not take into account of actual spatial variability of the soil and the rice varieties. Using the same parameter datasets in each region would make the data simulation less certain. Besides, the uncertainties of human factors, the randomness of data collection and regional heterogeneity of the initial conditions could lead to greater uncertainty of the simulation results. This realization required us to take careful management measures and control variables in the field experiment in order to ensure the consistency of the unified treatments and reduce the influence of human factors. We should also take more extreme weather events on the growth and yield into consideration, such as high temperature and drought. To circumvent these issues, the integration monitoring data with remote-sensing and climate-change models could further help to reduce the model uncertainties.

\section{Conclusion}

In this study, the ORYZA (v3) model was regionalized for Liaoning province. Both graphical and statistical tools were used to test for the model. It was indicated that the performance of the ORYZA (v3) model was overall satisfactory in simulating grain yield and biomass dynamics for rice in Liaoning province. However, the simulation of LAI was sub-optimal, which still needed to be improved in the future research. The scenario analyses using historical weather data from the last 35 years suggested that the $\mathrm{N}$-application rates had greater impacts on rice yield. For Yck to Yfp, the grain yields were increased by $2061 \mathrm{~kg} \mathrm{ha}^{-1}, 2118 \mathrm{~kg} \mathrm{ha}^{-1}, 3439 \mathrm{~kg} \mathrm{ha}^{-1}, 3168 \mathrm{~kg} \mathrm{ha}^{-1}, 3480 \mathrm{~kg} \mathrm{ha}^{-1}$ in CL1-CL5, respectively. However, the increased amplitude declined with the application of $\mathrm{N}$ fertilizer. In addition, different effects on grain-yield by $\mathrm{N}$ fertilizer were clearly associated with the regional characteristics. Areas with obvious increasing yield-trends were areas under better conditions of thermal resources and sunshine. Application of $\mathrm{N}$ fertilizer is crucial to obtaining appropriate crop yields without unnecessary expenses and waste of resources. Reasonable nitrogen application rate is preferable from the environmental and economic viewpoints. Current agriculture requires further research on how to make nitrogen fertilizer input more reasonable to achieve optimal crop management. This study can provide more valuable insights into future $\mathrm{N}$ fertilizer management analysis.

Acknowledgments. This study was supported by the National Key Research and Development Project of China (2016YFD0300104), Scientific research project of Liaoning Provincial Department of Education (LSNJC201905) and the National Natural Science Foundation of China (31771673).

\section{REFERENCES}

[1] Angstrom, A. (1924): Solar and terrestrial radiation. Report to the international commission for solar research on actinometric investigations of solar and atmospheric radiation. - Quarterly Journal of the Royal Meteorological Society 50(210): 121-126.

[2] Arora, V. K. (2005): Application of a rice growth and water balance model in an irrigated semi-arid subtropical environment. - Agricultural Water Management 83: 51-57. 
[3] Belder, P., Bouman, B. A. M., Cabangon, R., Lu, G., Quilang, E. J. P., Li, Y., Spiertz, J. H. J., Tuong, T. P. (2004): Effect of water-saving irrigation on rice yield and water use in typical lowland conditions in Asia. - Agricultural Water Management 65: 193-210.

[4] Black, J. N., Bonython, C. W., Prescott, J. A. (1954): Solar radiation and the duration of sunshine. - Quarterly Journal of the Royal Meteorological Society 80: 231-235.

[5] Bouman, M., van Laar, H. H. (2001): ORYZA2000: modeling lowland rice. - Los Baños: International Rice Research Institute, \& Wageningen: Wageningen University \& Research Centre, $235 \mathrm{Pp}+\mathrm{Cd}$-rom.

[6] Bouman, B. A. M., van Laar, H. H. (2004): Description and evaluation of the rice growth model ORYZA2000 under nitrogen-limited conditions. - Agricultural Systems 87(3): 249-273.

[7] Buresh, R., Witt, C. (2002): Challenge and Opportunity in Improving Fertilizer-nitrogen Use Efficiency of Irrigated Rice in China. - Agricultural Sciences in China 7: 67-76.

[8] Cao, H. X., Zhang, C. L., Li, G. M., Zhang, B. J., Zhao, S. L., Wang, B. Q., Jin, Z. Q. (2006): Researches of simulation models of rape (Brassica napus L.) growth and development. - Acta Agronomica Sinica 32: 1530-1536.

[9] Chen, J., Huang, Y., Tang, Y. (2011): Quantifying economically and ecologically optimum nitrogen rates for rice production in south-eastern China. - Agriculture Ecosystems \& Environment 142: 195-204.

[10] Chen, W., Liu, L., Liu, G. Y., Tai, E., Jin, F., Jia, G. (2019): Experimental study on alternate dry-wet irrigation of rice in middle area of Liaoning Province. - Hydro Science and Cold Zone Engineering 2: 6-11.

[11] Cheng, W., Lv, J., Xie, J., Yu, J., Li, J., Zhang, J., Tang, C., Niu, Bakpa, E. (2021): Effect of slow-release fertilizer on soil fertility and growth and quality of wintering Chinese chives (Allium tuberm Rottler ex Spreng.) in greenhouses. - Scientific reports 11 (1): 8070.

[12] Confalonieri, R., Bregaglio, S., Acutis, M. (2016): Quantifying uncertainty in crop model predictions due to the uncertainty in the observations used for calibration. - Ecological Modelling 328: 72-77.

[13] Evers, J. B., Vos, J., Fournier, C., Andrieu, B., Chelle, M., Struik, P. C. (2005): Functional-Structural Plant Modelling \|| Towards a Generic Architectural Model of Tillering in Gramineae, as Exemplified by Spring Wheat (Triticum aestivum L.). - New Phytologist 166: 801-812.

[14] Fan, X. R., Tang, Z., Tan, Y. W., Zhang, Y., Luo, B. B., Yang, M., Lian, X. M., Shen, Q. R., Miller, A. J., Xu, G. H. (2016): Overexpression of a pH-sensitive nitrate transporter in rice increases crop yields. - Proceedings of the National Academy of Sciences 113: 71187123.

[15] Feng, L. P., Bouman, B. A. M., Tuong, T. P., Cabangon, R. J., Li, Y. L., Lu, G. A., Feng, Y. H. (2007): Exploring options to grow rice using less water in northern China using a modelling approach: I. Field experiments and model evaluation. - Agricultural Water Management 88: 1-13.

[16] Gaiser, T., de Barros, I., Sereke, F., Lange, F-M. (2010): Validation and reliability of the EPIC model to simulate maize production in small-holder farming systems in tropical sub-humid West Africa and semi-arid Brazil. - Agriculture, Ecosystems \& Environment 135(4): 318-327.

[17] Guo, E. J., Yang, X. G., Wang, X. Y., Zhang, T. Y., Huang, W. H., Liu, Z. Q., Li, T. (2017): Spatial-Temporal Distribution of Double Cropping Rice's Yieldr Gap in Hunan Province. - Scientia Agricultura Sinica 50: 399-418.

[18] Kim, J., Sang, W., Shin, P., Cho, H., Kim, K. S. (2015): Evaluation of regional climate scenario data for impact assessment of climate change on rice productivity in Korea. Journal of Crop Science Biotechnology 18: 257-264. 
[19] Kropff, M. J., van Laar, H. H., Matthews, R. B. (1994): ORYZA1: An ecophysiological model for irrigated rice production. - DLO-Research Institute for Agrobiology and Soil Fertility, Wageningen. ISBN 9789073384231. https://edepot.wur.nl/297737

[20] Li, T., Raman, A. K., Marcaida, M., Kumar, A., Angeles, O., Radanielson, A. M. (2013): Simulation of genotype performances across a larger number of environments for rice breeding using ORYZA2000. - Field Crops Research 149: 312-321.

[21] Li, T., Jauhar, A., Manuel, M., Olivyn, A., Johann, F. N., Edrian, R. J., Emmali, M., Edilberto, R. A., Xu, J., Li, Z. (2016): Combining Limited Multiple Environment Trials Data with Crop Modeling to Identify Widely Adaptable Rice Varieties. - Plos One 11: e0164456.

[22] Li, T., Angeles, O., Marcaida, M., Manalo, E., Manalili, M. P., Radanielson, A., Mohanty, S. (2017): From ORYZA2000 to ORYZA (v3): An improved simulation model for rice in drought and nitrogen-deficient environments. - Agricultural \& Forest Meteorology 237-238: 246-256.

[23] Ling, X., Zhang, T., Deng, N., Yuan, S., Huang, J. (2019): Modelling rice growth and grain yield in rice ratooning production system. - Field Crops Research 241: 107574.

[24] Liu, J. L., Song, J. J., Li, F. L., Liu, S. Q. (2000): Effects of Nitrogen application amount on soil fertility and plant nutrient content and yield of paddy rice. - Agriculture and Technology 4: 8-12.

[25] Liu, H. L., Yang, J. Y., Drury, C. F., Reynolds, W. D., Tan, C. S., Bai, Y. L., He, P., Jin, J. (2011): Using the DSSAT-CERES-Maize model to simulate crop yield and nitrogen cycling in fields under long-term continuous maize production. - Nutrient Cycling in Agroecosystems 89: 313-328.

[26] Mae, T. (1997): Physiological nitrogen efficiency in rice: Nitrogen utilization, photosynthesis, and yield potential. - Plant Soil 196: 201-210.

[27] Mao, X. Y., Sun, K. J., Wang, D. H., Liao, Z. W. (2005): Controlled-release fertilizer (CRF): a green fertilizer for controlling non-point contamination in agriculture. - Journal of environmental sciences (China) 17: 181-184.

[28] National Bureau of Statistics of China (2016): China Statistical Yearbook. - China Statistics Press, Beijing.

[29] Peng, S., Buresh, R. J., Huang, J., Zhong, X. (2010): Improving nitrogen fertilization in rice by sitespecific N management. A review. - Agronomy for Sustainable Development 30: 649-656.

[30] Rani, Y. S., Jayasree, G., Sesha Sai, M. V. R., Reddy, M. D. (2011): Impact of Climate Change on Rice Production in Nalgonda District, Andhra Pradesh using ORYZA 2000 Model. - Journal of Rice Research 4: 21-26.

[31] Roelcke, M., Yong, H., Schleef, K. H., Zhu, J. G., Gang, L., Cai, Z. C., Richter, J. (2004): Recent Trends and Recommendations for Nitrogen Fertilization in Intensive Agriculture in Eastern China. - Pedosphere 14: 449-460.

[32] Shen, Y. Z., Zhang, Z. L., Qian, X. Q., Wu, J. Y., Dong, K. J., Liu, B. X., Jiang, S. Q., Li, J. (1994): Nitrogen nutrition characteristics and fertilization in high yield rice. - Chinese Journal of Soil Science 2: 78-80.

[33] Soundharajan, B., Sudheer, K. P. (2013): Sensitivity analysis and auto-calibration of ORYZA2000 using simulation-optimization framework. - Paddy and Water Environment 11: 59-71.

[34] Stockle, C. O., Martin, S. A., Campbell, G. S. (1994): CropSyst, a cropping systems simulation model: water/nitrogen budgets and crop yield. - Agricultural Systems 46: 335359.

[35] Tilman, D., Balzer, C., Hill, J., Befort, B. L. (2011): Global food demand and the sustainable intensification of agriculture. - Proceedings of the National Academy of ences of the United States of America 108: 20260-20264.

[36] Wang, Y. (2017): Analysis of rice yield and fertilizer utilization rate under conventional fertilization in Liaoning Province. - China Agricultural Technology Extension 33: 36-39. 
[37] Wang, Y. H., Han, X. R., Wang, L., Yu, X. H. (2010): Study of Fertilizers' Effect on Rice and Function Models of Fertilizer Recommendation in the Panjin District of China. Chinese Journal of Soil Science 41: 373-378.

[38] York, L. M., Silberbush, M., Lynch, J. P. (2016): Spatiotemporal variation of nitrate uptake kinetics within the maize (Zea mays L.) root system is associated with greater nitrate uptake and interactions with architectural phenes. - Journal of experimental botany 67(12): 3763-75.

[39] Yu, G. X., Sui, G. M., Peng, S. B., Hou, S. G., Chen, Y. (2009): Effects of site-specific nitrogen management techniques on rice growth and nitrogen utilization rate. - Liaoning Agricultural Sciences, 1-4. 